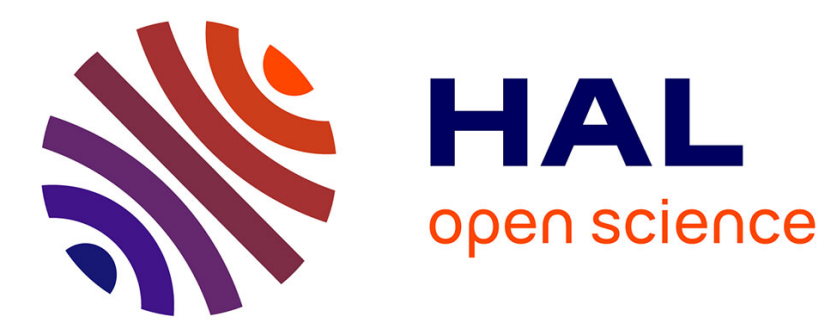

\title{
Adsorption capacity of the corrosion products of nanoscale zerovalent iron towards emerging contaminants
}

Junmin Deng, Sungjun Bae, Sunho Yoon, Mathieu Pasturel, Remi Marsac, Khalil Hanna

\section{To cite this version:}

Junmin Deng, Sungjun Bae, Sunho Yoon, Mathieu Pasturel, Remi Marsac, et al.. Adsorption capacity of the corrosion products of nanoscale zerovalent iron towards emerging contaminants. Environmental science.Nano, 2020, 7 (12), pp.3773-3782. 10.1039/d0en00886a . insu-02986605v2

\section{HAL Id: insu-02986605 \\ https://hal-insu.archives-ouvertes.fr/insu-02986605v2}

Submitted on 18 Dec 2020

HAL is a multi-disciplinary open access archive for the deposit and dissemination of scientific research documents, whether they are published or not. The documents may come from teaching and research institutions in France or abroad, or from public or private research centers.
L'archive ouverte pluridisciplinaire HAL, est destinée au dépôt et à la diffusion de documents scientifiques de niveau recherche, publiés ou non, émanant des établissements d'enseignement et de recherche français ou étrangers, des laboratoires publics ou privés. 
4 Junmin Deng1,2, Sungjun Bae², Sunho Yoon², Mathieu Pasturel ${ }^{3}$, Rémi Marsac ${ }^{4}$, Khalil Hanna ${ }^{1,5^{*}}$

${ }^{1}$ Univ. Rennes, Ecole Nationale Supérieure de Chimie de Rennes, CNRS, ISCR-UMR

${ }^{2}$ Department of Civil and Environmental Engineering, Konkuk University, 120 Neungdong-ro, Gwangjin-gu, Seoul 05029, Republic of Korea 


\section{Abstract}

Despite the extensive use of nanoscale zerovalent iron (NZVI) in water and soil

23 remediation, no data exist on the reactivity of secondary iron minerals formed upon the

24 NZVI corrosion. Herein, we investigated the oxidation kinetics of NZVI by monitoring

25 the variations of $\mathrm{pH}$, oxidation-reduction potential (ORP) and dissolved $\mathrm{Fe}(\mathrm{II})$

26 concentration, and then examined the reactivity of resulting oxidized particles for the

27 adsorption of an emerging contaminant (nalidixic acid (NA)). NA adsorption was found

28 greatest onto oxidized particles and negligible on the fresh NZVI. Interestingly, the

29 formed secondary mineral phases exhibited an unusual $\mathrm{pH}$ adsorption-curve with an

30 unexpected great adsorption at alkaline $\mathrm{pH}$ values. X-ray photoelectron spectroscopy

31 and high resolution-transmission electron microscopy revealed a gradual increase in

$32 \mathrm{Fe}(\mathrm{II})$ content at the surface of magnetite phase over the reaction time. Additional

33 experiments and surface complexation modeling showed that the enhanced adsorption

34 of NA onto the secondary magnetite is due to the formation of surface bound Fe(II).

$35 \mathrm{Fe}(\mathrm{II})$ release into solution because, for instance, of the presence of organic buffer

36 molecules, decreased surface Fe(II) and then NA adsorption at alkaline pH values. This

37 work sheds light on an overseen aspect of the reactivity of secondary iron minerals

38 resulting from NZVI passivation, which can bind co-exiting emerging contaminants

39 and then affect their fate in the environment. 


\section{Introduction}

Because nanoscale zerovalent iron (NZVI) is an environmentally-safe material and

42

43

44

45 has been extensively investigated, little is known about the fate of injected NZVI

exhibits great particle reactivity, it has been widely used in treatment processes of various organic and inorganic contaminants ${ }^{1-3}$. As a result, NZVI has become one of the most extensively studied nanomaterials in wastewater treatment and remediation of soil and groundwater. ${ }^{4-7}$

For the remediation action, the NZVI slurry is directly introduced into soil and groundwater systems, and NZVI particles migrate from the injection points to affected zones. ${ }^{8}$ During this journey, NZVI could encounter many electron acceptors resulting in partial or complete oxidation of NZVI particles (also called surface passivation). These electron acceptors may include oxygen as in oxic environments, nitrate, etc. and targeted compounds, i.e. contaminants. ${ }^{9-12}$ This oxidation can lead to either formation of $\mathrm{Fe}^{\mathrm{II}}$-bearing phases on the NZVI surface or complete oxidation to ferric (oxyhydr)oxides, depending upon various factors including type and concentration of co-existing species, reaction time and oxic/anoxic environments. For instance, lepidocrocite, magnetite and maghemite appeared to be the main secondary iron minerals formed upon the oxic corrosion of NZVI. ${ }^{13}$

Although the ability of NZVI to reductively transform a wide variety of compounds particles in natural systems. In addition, NZVI passivation byproducts have been 
identified under oxic and anoxic conditions, ${ }^{14}$ but no data exist on the reactivity of these

61 byproducts in nature. Indeed, the passivation byproducts (i.e., secondary Fe minerals)

62 would continue to migrate in environmental settings and potentially meet other types

63 of contaminants. They could bind co-existing contaminants and then influence their

64 aqueous or colloidal transport in soil and groundwater. Comprehensive examination of

65 the reactivity of these "abandoned" particles and their mobility in natural settings is

66 essential for ecological risk assessments.

67 Here, we examined the interactions between NZVI (fresh or passivated) and

68 nalidixic acid (NA), a quinolone antibiotic widely used in human and veterinary

69 medicine. NA was selected as a target emerging contaminant because it has been

70 frequently detected in the environment (at concentration levels ranging from $\mathrm{ng} \cdot \mathrm{L}^{-1}$ to

$\left.71 \mu \mathrm{g} \cdot \mathrm{L}^{-1}\right) .{ }^{15,16}$ To control the NZVI oxidation in aqueous suspension, hydrogen peroxide

$72\left(\mathrm{H}_{2} \mathrm{O}_{2}\right)$ was used under anoxic conditions ( $\mathrm{N}_{2}$ glove box). $\mathrm{pH}$ and oxidation-reduction

73 potential (ORP) values and dissolved Fe(II) concentration were measured throughout

74 the reaction, and transformation of NZVI particles were monitored by X-ray diffraction,

75 X-ray photoelectron spectroscopy and high resolution-transmission electron

76 microscopy (HR-TEM) equipped with the selected area electron diffraction (SAED).

77 Adsorption tests were performed after total depletion of $\mathrm{H}_{2} \mathrm{O}_{2}$ in order to prevent any

78 contribution from Fenton-like oxidation (mass balance was also checked) in NA

79 removal. NA adsorption onto the resulting oxidized NZVI particles was evaluated as a

80 function of $\mathrm{pH}$ and NA concentration. A surface complexation model was used to 
81 account for the impact of $\mathrm{Fe}(\mathrm{II})$ content on the NA adsorption into secondary Fe 82 minerals.

\section{Materials and methods}

84

85

\subsection{Chemicals and materials}

Nalidixic acid (NA, $\geq 99.0 \%$ ), sodium borohydride $\left(\mathrm{NaBH}_{4}, \geq 99.0 \%\right.$ ), ferric chloride hexahydrate $\left(\mathrm{FeCl}_{3} \cdot 6 \mathrm{H}_{2} \mathrm{O}, \geq 99.0 \%\right)$, hydrogen peroxide solution $\left(\mathrm{H}_{2} \mathrm{O}_{2}, 30 \%\right)$, ferrous chloride tetrahydrate $\left(\mathrm{FeCl}_{2} \cdot 4 \mathrm{H}_{2} \mathrm{O}, \geq 99.0 \%\right), 1,10$-phenanthroline ( $\left.\geq 99.0 \%\right)$, acetic acid ( $\geq 99.5 \%$ ), hydrochloric acid ( $\mathrm{HCl}, 37 \%)$, sodium hydroxide ( $\mathrm{NaOH}$, $\geq 99.0 \%$ ), glycerol $(\geq 99.5 \%)$, tetracycline hydrochloride (TET, $\geq 99.0 \%$ ), 4morpholineethanesulfonic acid (MES, $\geq 99.5 \%$ ), 4-(2-hydroxyethyl)piperazine-1ethanesulfonic acid (HEPES, $\geq 99.5 \%$ ), tris(hydroxymethyl)aminomethane (TRIZMA base, $\geq 99.9 \%$ ) and Tris(hydroxymethyl)aminomethane hydrochloride (TRIZMA HCl, $\geq 99.5 \%$ ) were all purchased from Sigma-Aldrich, France. Leonardite Humic Acid standard (LHA) was purchased from the International Humic Substances Society (IHSS). Maghemite $\left(\gamma-\mathrm{Fe}_{2} \mathrm{O}_{3}\right)$ was purchased from Alfa Aesar, with a high purity (>99.0\%). Magnetite $\left(\mathrm{Fe}_{3} \mathrm{O}_{4}\right)$, hematite $\left(\alpha-\mathrm{Fe}_{2} \mathrm{O}_{3}\right)$ and lepidocrocite $(\gamma$-FeOOH) were synthesized as previously reported. ${ }^{17}$ Acetonitrile (99.99\%, Sigma) and acetic acid (99.7\%, ACROS) were used for mobile phase of high-performance liquid chromatography (HPLC). NA stock solution (5 mM) and ferrous chloride stock solution (100 mM) were prepared with $0.1 \mathrm{M} \mathrm{NaOH}$ and $0.1 \mathrm{M} \mathrm{HCl}$, respectively. Glassware 
101

103

104

105

106

108

109

110

111

112

113

114

115

116

117 surface oxidation during the analysis of $\mathrm{XRD} \cdot{ }^{19} \mathrm{X}$-ray photoelectron spectroscopy

118 (XPS, Sigma Probe system, Thermo) analysis was performed for four different samples

119 (i.e., pristine NZVI, NZVI after reaction with $\mathrm{H}_{2} \mathrm{O}_{2}(3,15$, and $18 \mathrm{~h})$. We used the power

120 source (Al Ka X-ray, $1486.7 \mathrm{eV}$ ) of $75 \mathrm{~W}$ and the $\mathrm{C} 1$ s peak at $285 \mathrm{eV}$ as a reference

121 for correction of surface charging effects. The morphological characterization of 
122 different oxidized NZVIs were investigated by high resolution-transmission electron

123 microscopy (HR-TEM, JEM-2100, JEOL) equipped with the selected area electron

124 diffraction (SAED). The specific surface area of oxidized NZVIs was analyzed by

125 multi-point $\mathrm{N}_{2}$ adsorption isotherm (Micromeritics, USA). The average particle size

126 and zeta potential of the oxidized NZVI particles were measured by Zetasizer MAS

127 (Matec Applied Sciences).

128

129 2.3. Analytical methods

130 Batch experiments were conducted in $500 \mathrm{~mL}$ flasks in anaerobic chamber to avoid

131 the effect of dissolved oxygen during the reaction. $0.1 \mathrm{~g}$ NZVI was transferred to the

132 flask containing $500 \mathrm{~mL}$ DDIW with stirring at $600 \mathrm{rpm}$ to prepare an initial NZVI

133 dosage of $200 \mathrm{mg} / \mathrm{L}$. A portable pH-ORP meter (HANNA, HI991003) was used to

134 monitor the variations in $\mathrm{pH}$ and ORP during the oxidation and adsorption processes.

135 After a steady state was reached for both $\mathrm{pH}$ and ORP, exact amounts $(0.25,0.5,1,2.5$

136 or $5 \mathrm{~mL}$ ) of $\mathrm{H}_{2} \mathrm{O}_{2}$ stock solution ( $1 \mathrm{M}$ ) were introduced into the suspensions to prepare

137 different oxidized NZVIs by different $\mathrm{H}_{2} \mathrm{O}_{2}$ concentration at $0.5,1,2,5$ or $10 \mathrm{mM}$,

138 respectively. After reaching the equilibrium of $\mathrm{pH}$ and ORP again, $1 \mathrm{~mL}$ of NA stock

139 solution ( $5 \mathrm{mM}$ ) was transferred into the suspension to initiate the adsorption of NA (10

$140 \mu \mathrm{M}$ ) by the oxidized NZVI. At the sampling times, $1 \mathrm{~mL}$ samples were taken from the

141 suspension and filtered through a $0.2 \mu \mathrm{m}$ filter (Whatman) for analysis of high- 
142 performance liquid chromatography (HPLC). After finishing 2-h adsorption, desorption

143 tests were carried out at $\mathrm{pH} 12$ to check the mass balance of NA (Table S1).

144 Aqueous concentration of NA was determined using HPLC (Waters 600 Controller)

145 equipped with a photodiode array detector operating at $258 \mathrm{~nm}$ (Waters 996) and a 146 reversed-phase C18 column $(250 \mathrm{~mm} \times 4.6 \mathrm{~mm}$ i.d., $5 \mu \mathrm{m})$. The mobile phase was a 147 mixture of acetonitrile/water (60/40 v/v) containing $0.1 \%$ formic acid. The flow rate of 148 the mobile phase was set at $1 \mathrm{~mL} / \mathrm{min}$ in isocratic mode. ${ }^{20}$ The dissolved Fe(II) 149 concentration was measured by a 1,10-phenanthroline method at a wavelength of 510 150 nm using an UV-vis spectrophotometer (U-3310, HITACHI).

151 The same procedure was used to investigate the oxidation of NZVI in buffered 152 systems. A constant Good's buffer (MES, HEPES and TRIZMA) concentration of 10 $153 \mathrm{mM}$ was used to maintain the $\mathrm{pH}$ at 5.6, 7.0 and 9.0, respectively ${ }^{21-22}$. These buffers 154 were introduced into the reactor together with NZVI (200 mg/L).

155 All experiments were performed in triplicates, and the data reported here were the 156 average of three replicated experiments and error bars represent the relative standard 157 deviation.

\subsection{Surface Complexation Modeling}

The NA removal in the NZVI suspension at different $\mathrm{pH}$ values were described

161 using surface complexation modeling. The geochemical speciation code PHREEQC

162 and the "minteq" database were used. ${ }^{23}$ The $\mathrm{pK}_{\mathrm{a}}$ of NA is 6.19 and the logarithm of the 
163 formation constant of $\mathrm{NA}-\mathrm{Fe}^{+}(\mathrm{aq})$ is $3.99 .{ }^{24}$ The surface complexation models for 164 magnetite are used, as previously reported, ${ }^{25}$ and the protonation of Fe surface sites is 165 formulated following a 2-pK $a$ approach (Eqs. (1) and (2)).

166

$$
\begin{aligned}
& \equiv \mathrm{FeOH}_{2}^{+} \leftrightharpoons \equiv \mathrm{FeOH}+\mathrm{H}^{+} ; p \mathrm{Ka}_{1} \\
& \equiv \mathrm{FeOH} \leftrightharpoons \equiv \mathrm{FeO}^{-}+\mathrm{H}^{+} ; p \mathrm{Ka}_{2}
\end{aligned}
$$

169

170 Charge-potential relationship was described according to the constant capacitance 171 model (CCM), and the modeling parameters are presented in the supporting information 172 (Table S2). Though the CCM is not available in PHREEQC (version 2), we have 173 adapted parameters of the three plane model (TPM) implemented in PHREEQC in 174 order to use the CCM, as previously reported. ${ }^{26}$

175

\section{3. Results and discussion}

\section{3.1. NZVI oxidation in aqueous solution and NA removal}

$178 \quad$ Variations in $\mathrm{pH}$, ORP and dissolved $\mathrm{Fe}(\mathrm{II})$ concentration were monitored during 179 i) the addition of NZVI in reactor, ii) the oxidation of NZVI by $\mathrm{H}_{2} \mathrm{O}_{2}$, and iii) the 180 removal of NA by the resulting secondary particles (Figure 1). When NZVI was added 181 in water (i.e., the first 2-h period), we observed an obvious increase in $\mathrm{pH}$ (from 6.9 to 182 8.9) and a decrease in ORP (from 81 to $-748 \mathrm{mV}$ ), which can be attributed to generation 
183

184

185

186

190

191

of $\mathrm{OH}^{-}, \mathrm{Fe}^{2+}$, and $\mathrm{H}_{2}$ during the anaerobic corrosion of NZVI (Eq.(3)). ${ }^{27}$

$$
\mathrm{Fe}^{0}+2 \mathrm{H}_{2} \mathrm{O} \rightarrow \mathrm{Fe}^{2+}+2 \mathrm{OH}^{-}+\mathrm{H}_{2}
$$

After adding $\mathrm{H}_{2} \mathrm{O}_{2}$ into the NZVI suspension, the ORP value increased rapidly up to $241 \mathrm{mV}$ due to the standard potential of $\mathrm{H}_{2} \mathrm{O}_{2} / \mathrm{H}_{2} \mathrm{O}(1.37 \mathrm{~V})^{28}$, while $\mathrm{pH}$ dropped to 7.8 which is ascribed to the oxidation and hydrolysis of released iron ions. In addition, the release of $\mathrm{H}^{+}$from $\mathrm{H}_{2} \mathrm{O}_{2}$ dissociation ( $\mathrm{pK}_{\mathrm{a}}$ of 11.6) presumably results in $\mathrm{pH}$ decrease. $^{29}$

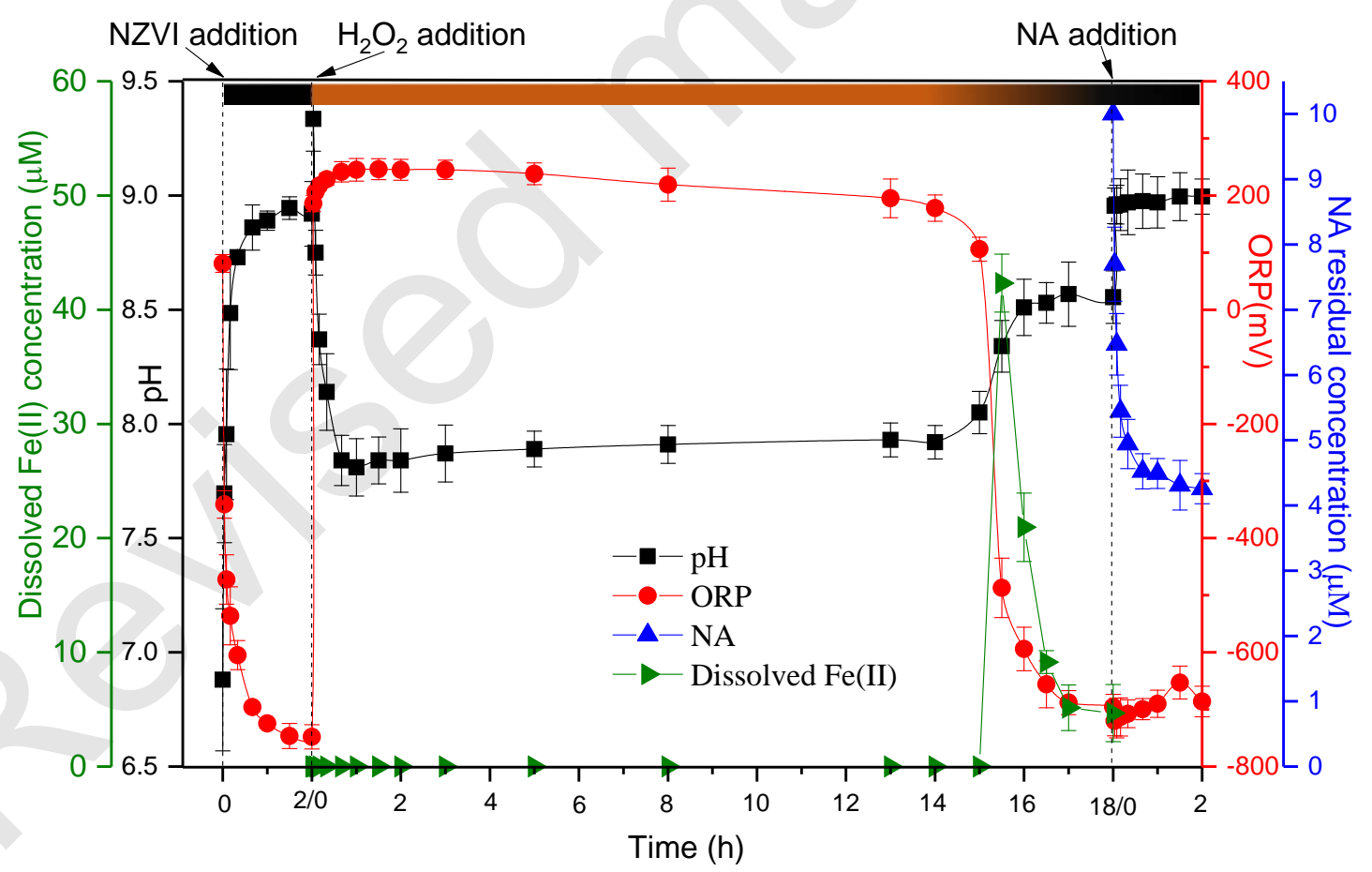

192

193 Figure 1. Variations in $\mathrm{pH}$, ORP, color of suspension, dissolved Fe(II) concentration 194 and NA concentration during the NZVI oxidation and NA adsorption. Experimental 195 conditions: $[\mathrm{NZVI}]=0.2 \mathrm{~g} \cdot \mathrm{L}^{-1},\left[\mathrm{H}_{2} \mathrm{O}_{2}\right]_{\text {initial }}=5 \mathrm{mM},[\mathrm{NA}]_{\text {initial }}=10 \mu \mathrm{M}, 20 \pm 1{ }^{\circ} \mathrm{C}$. 

dissolved Fe(II) during that period.

$$
\mathrm{Fe}^{0}+\mathrm{H}_{2} \mathrm{O}_{2}+2 \mathrm{H}^{+} \leftrightharpoons \mathrm{Fe}^{2+}+2 \mathrm{H}_{2} \mathrm{O}
$$

Once $\mathrm{H}_{2} \mathrm{O}_{2}$ was totally consumed and ORP reached again negative values, release of dissolved Fe(II) into solution was observed. Then, the dissolved Fe(II) concentration decreased over reaction time, likely due to adsorption to oxide particles, particularly at high $\mathrm{pH}$ value ( 8). It is worth noting that the color of suspension changed from black

211 to yellow after the addition of $\mathrm{H}_{2} \mathrm{O}_{2}$, and gradually turned to black after the 15-h 212 reaction. Once the ORP and $\mathrm{pH}$ values reached steady-state values, a desired concentration 214 of NA was introduced into the reaction system, and residual NA concentration was 215 monitored over time (Figure 1). A slight increase in $\mathrm{pH}$ can be mainly attributed to the 216 alkalinity of the NA mother solution, but also to NA binding to oxide surfaces. Indeed, 
217 almost $60 \%$ of NA removal was observed after $2 \mathrm{~h}$ of reaction time at the working $\mathrm{pH}$

218 ( 9). NA removal by, for instance, Fenton-like oxidation is excluded under our 219 experimental conditions, since full mass balance was achieved at the end of reaction, 220 i.e. desorbed amounts equivalent to adsorbed ones (Table S1). This great adsorption 221 ( 29 $\mu$ mol per g of initial NZVI added) at an alkaline $\mathrm{pH}$ is quite unusual, and thus not 222 comparable with the typical pH-dependence behavior of adsorption of 223 monocarboxylates or polyfunctional compounds, as for example quinolones. ${ }^{20}$ Indeed, 224 the sorption behavior of such compounds to metal oxides is generally attributed to a 225 combination of $\mathrm{pH}$-dependent speciation of compound (e.g. $\mathrm{pK}_{\mathrm{a}}$ of $\left.\mathrm{NA}=6.19\right)$ and 226 surface charge characteristics of the mineral oxide (PZC of Fe-oxyhyrdoxides is 227 generally between 8 and 9.5). ${ }^{20}$ As a result, adsorption is generally high at low $\mathrm{pH}$ value 228 and then decreases when $\mathrm{pH}$ increases, and becomes negligible at $\mathrm{pH}$ higher than $10 .{ }^{33}$ 229 Here, the NA adsorption is unusually high at $\mathrm{pH}$ around 9, and even increased from 29 230 to $40 \mu \mathrm{mol} / \mathrm{g}$ when the initial NA concentration increased from 10 to $20 \mu \mathrm{M}$, further 231 confirming the high affinity of the NZVI oxidation products toward NA.

\section{3.2. Secondary minerals formation and impacts on NA removal}

234 NZVI can be oxidized and/or transformed into different iron oxides depending on

235 the oxidant dose, which may exhibit contrasting affinities towards NA. For this reason, 236 additional experiments of NZVI oxidation were performed with different $\mathrm{H}_{2} \mathrm{O}_{2}$ 237 concentrations (Figure S1). Generally, higher $\mathrm{H}_{2} \mathrm{O}_{2}$ concentration led to a rapid increase 
238 in ORP value in NZVI suspension, and then decrease to reach the initial value, except

239 for the highest $\mathrm{H}_{2} \mathrm{O}_{2}$ dose. For the sake of clarity, only the last stage, i.e. NA adsorption,

240 was shown and the adsorbed amount of NA was plotted versus time for different $\mathrm{H}_{2} \mathrm{O}_{2}$

241 concentrations (0 - $10 \mathrm{mM}$ ) (Figure 2a). Interestingly, a negligible removal of NA was

242 observed on the fresh NZVI, while the NA removal amount onto the resulting secondary

243 minerals increased with increasing in $\mathrm{H}_{2} \mathrm{O}_{2}$ dose, yet no significant difference was

244 observed for the two highest doses (5 and $10 \mathrm{mM}$ ). It is interesting to note that the NA

245 removal amount by the corrosion particles of NZVI can be enhanced in the presence of

246 humic acid (LHA was used here as model of natural organic matter) (see Figure S3).

247 Indeed, the presence of $5 \mathrm{mg} / \mathrm{L}$ of LHA increased the NA adsorbed amount from 22 to

$24830 \mu \mathrm{mol} / \mathrm{g}$. This enhanced adsorption in the presence of humic acids can be ascribed to

249 better dispersion of secondary mineral particles, thus increasing available surface area

250 as previously reported. ${ }^{34}$ 

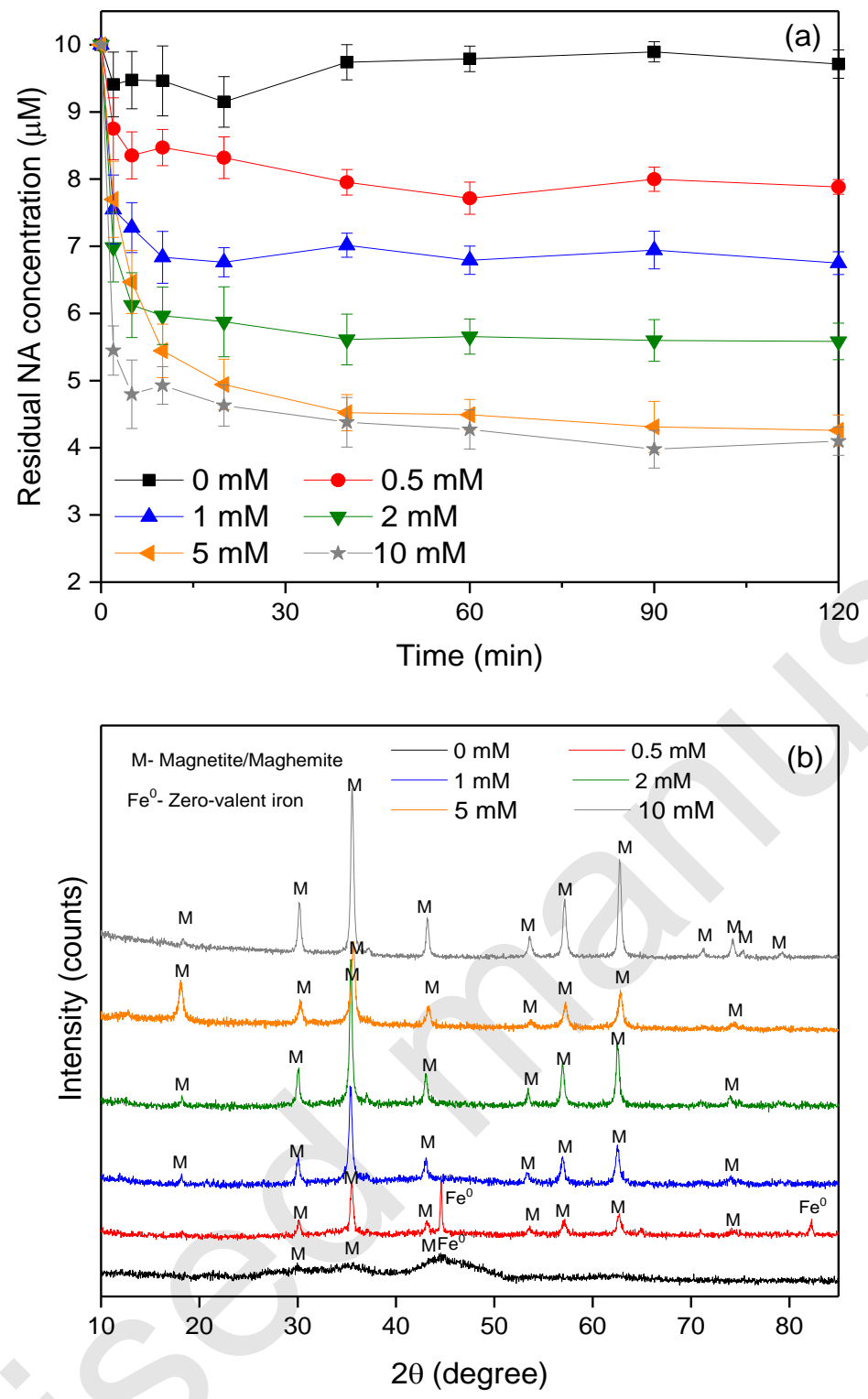

252 Figure 2. (a) NA removal by the oxidation NZVI samples (b) XRD patterns of 253 secondary minerals at different $\mathrm{H}_{2} \mathrm{O}_{2}$ concentrations $(0-10 \mathrm{mM})$; unbuffered systems $254(\mathrm{pH}=9 \pm 0.2$ for the adsorption stage $) ;[\mathrm{NZVI}]=0.2 \mathrm{~g} \cdot \mathrm{L}^{-1},[\mathrm{NA}]_{\text {initial }}=10 \mu \mathrm{M}, 20 \pm 1{ }^{\circ} \mathrm{C}$. As the adsorption capacity is closely related to the properties of iron oxides and 257 hydroxides, the resulting secondary minerals were firstly characterized by XRD (Figure 2b). The XRD pattern of fresh NZVI revealed the presence of a broad peak of $\alpha$-Fe 
$259\left(44.5^{\circ} 2 \theta\right)$ with weak peaks of magnetite and/or maghemite (marked as M) due probably 260 to outer iron oxide shell of NZVI particles. ${ }^{18}$ At low $\mathrm{H}_{2} \mathrm{O}_{2}$ concentration $(0.5 \mathrm{mM})$, 261 peaks of $\alpha$-Fe were still observed while new peaks corresponding to magnetite and/or 262 maghemite appeared. At $\mathrm{H}_{2} \mathrm{O}_{2}$ concentration over $1 \mathrm{mM}$, magnetite/maghemite was 263 detected as the major secondary iron minerals (Figure 2b).

264 To gain more insight about potential changes in surface properties upon NZVI 265 oxidation, zeta potential and average particle size of the secondary mineral particles 266 were measured. These results showed that $\mathrm{H}_{2} \mathrm{O}_{2}$ induced oxidation may influence the 267 aggregation behavior in NZVI suspension (Figure S2). While Zeta potential negative 268 value is within the reported values for bare NZVI at alkaline pH (9), ${ }^{35} \mathrm{H}_{2} \mathrm{O}_{2}$ induced 269 oxidation resulted in a significant reduction of the mean size of agglomerates from 270 around $4000 \mathrm{~nm}$ to around $800 \mathrm{~nm}$ when the $\mathrm{H}_{2} \mathrm{O}_{2}$ concentration exceeded $2 \mathrm{mM}$.

271 However, the zeta potential of NZVI suspension did not change significantly over the 272 entire $\mathrm{H}_{2} \mathrm{O}_{2}$ concentration range. Generally, increasing in negative surface charge of 273 particles may indicate dispersion or lower aggregation. ${ }^{36}$ Here, enhancement in the 274 electrostatic repulsion effect and thus the dispersion of the particles is only observed at 275 higher $\mathrm{H}_{2} \mathrm{O}_{2}$ dose, that could be associated with the formation of magnetite/maghemite 276 particles (Fig. 2b). The high agglomeration observed for the fresh NZVI or slightly 277 oxidized NZVI could be possibly due to electrostatic attractions between various kinds 278 of particles: $\mathrm{Fe}^{0}$, iron oxides coating the $\mathrm{Fe}^{0}$ core and other secondary minerals. 279 Furthermore, the van der Waals interactions between these particles may take place 
280 because of the limited electrostatic repulsion between particles. Accordingly, the BET

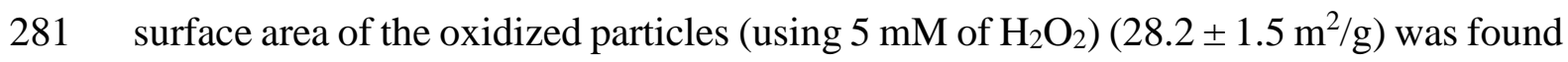
282 almost twice higher than the surface area of the fresh NZVI $\left(14.9 \pm 1 \mathrm{~m}^{2} / \mathrm{g}\right)$.

283 Collectively, these results suggest that fresh NZVI (or $\mathrm{Fe}^{0}$ ) has negligible affinity 284 for NA adsorption, and the secondary Fe minerals could be responsible of the NA 285 removal in NZVI suspension.

\subsection{Structural evolution of NZVI over reaction time}

As the highest removal rate of NA was observed with a high dose of $\mathrm{H}_{2} \mathrm{O}_{2}$ (5 or

$28910 \mathrm{mM}$ ), we have investigated the morphological changes of oxidized NZVI particles over reaction time when $5 \mathrm{mM}$ of $\mathrm{H}_{2} \mathrm{O}_{2}$ was used for oxidation. Two key stages of NZVI

291 oxidation kinetics were investigated (as shown in Figure 1) : (i) 3h, after $\mathrm{H}_{2} \mathrm{O}_{2}$ addition 292 and when ORP and $\mathrm{pH}$ values have reached a plateau (oxidizing conditions), and (ii)

293 18h just before NA addition and when ORP and $\mathrm{pH}$ values have reached constant values 294 after complete $\mathrm{H}_{2} \mathrm{O}_{2}$ depletion. 

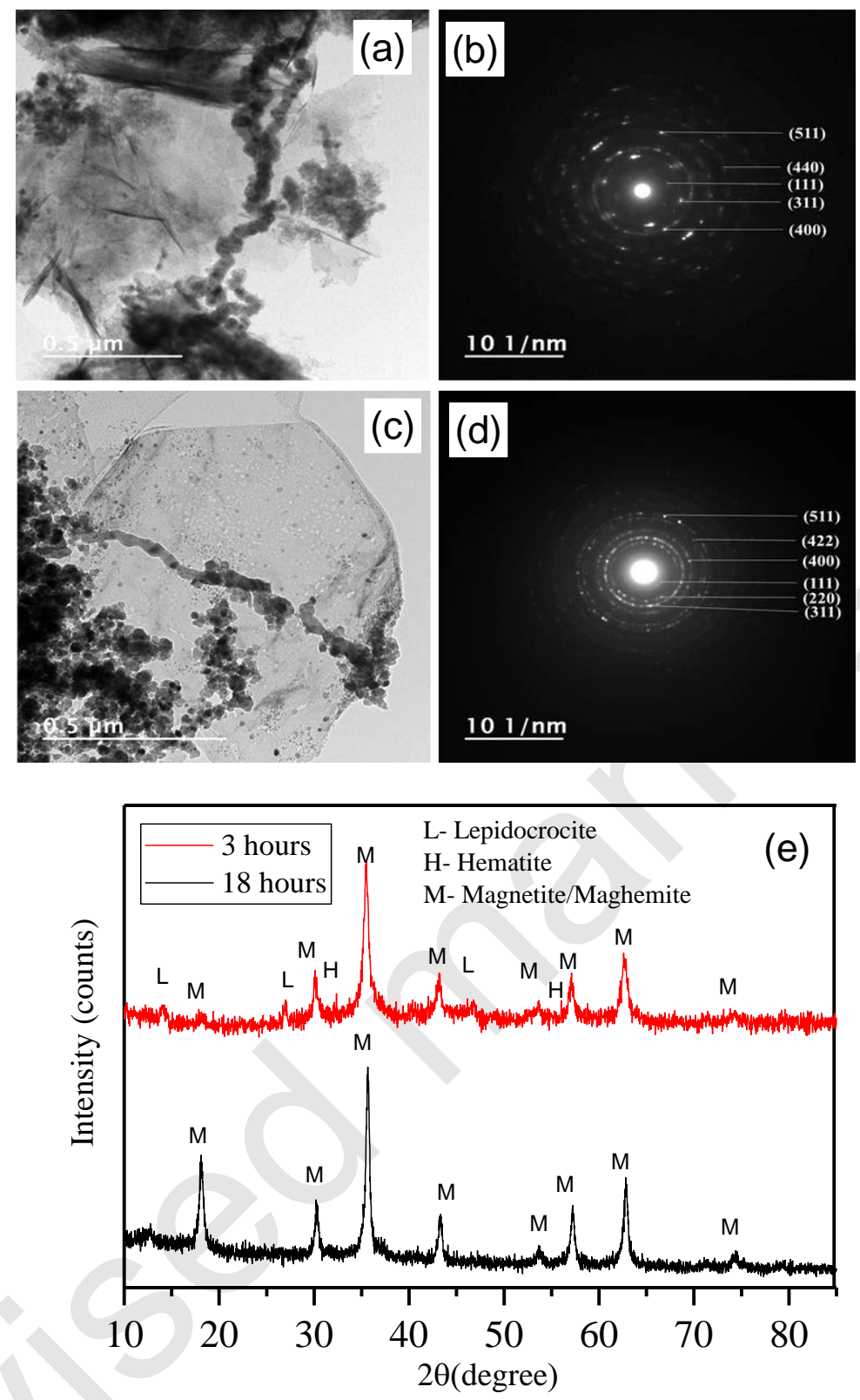

297 Figure 3. TEM images and SEAD pattern of the oxidized NZVI with $5 \mathrm{mM} \mathrm{H}_{2} \mathrm{O}_{2}$ at 298 two oxidation times (a and b) 3 hours and (c and d) 18 hours, and (e) corresponding 299 XRD patterns.

301 In the 3-h sample, we observed the presence of chain-like aggregates of nanoparticles 302 and needle-like shaped individual nanoparticles (Figure 3). The SAED pattern of chain- 
303 like aggregates (Figure 3b) showed the d-spacing of 4.87, 2.53, 2.09, 1.60 and $1.49 \AA$, 304 which are assigned to the (111), (311), (400), (511), and (440) of magnetite/maghemite 305 phase, respectively. ${ }^{37}$ In addition, the XRD of 3-h sample revealed the presence of peaks 306 of magnetite/maghemite, lepidocrocite, and hematite (Figure 3e). This is consistent 307 with previous investigation, which showed that needle-shaped lepidocrocite was 308 formed as a secondary product from NZVI oxidation in oxygenated water. ${ }^{38}$ TEM 309 image of $18 \mathrm{~h}$ oxidized NZVI (Figure 3c) shows the presence of nanoparticles 310 aggregates without other distinct shaped particles. Single nanoparticles (20 nm as an 311 average size) were connected to form chain-like magnetic nanoparticles (see Figure S4).

312 The SAED pattern of these aggregates revealed the reflections of (111, $4.87 \AA$ ), (220, $3132.98 \AA),(311,2.53 \AA),(400,2.08 \AA),(422,1.70 \AA)$, and (511, $1.59 \AA)$, corresponding 314 to magnetite or maghemite. ${ }^{39}$ Though these minerals both have indistinguishable 315 diffraction patterns, the chain-like assembly of these nanoparticles may suggest strong 316 ferromagnetic properties of particles at room temperature. Because the weak dipole317 dipole interactions between the maghemite particles are usually not sufficient to result 318 in the chain formation, the chain assemblies observed here tend to support the formation 319 of magnetite as the dominant phase. ${ }^{40,41}$ This falls in line with previous report, ${ }^{42}$ where 320 magnetite has been detected as the major secondary iron mineral under anoxic 321 conditions (i.e. equivalent to conditions here within the $15 \mathrm{~h}-18 \mathrm{~h}$ period of reaction). In 322 addition, the oxidation of NZVI to magnetite $\left(\mathrm{Fe}_{3} \mathrm{O}_{4}\right)$ seems to be more 323 thermodynamically favorable at alkaline $\mathrm{pH}$ values. ${ }^{23,43}$ 

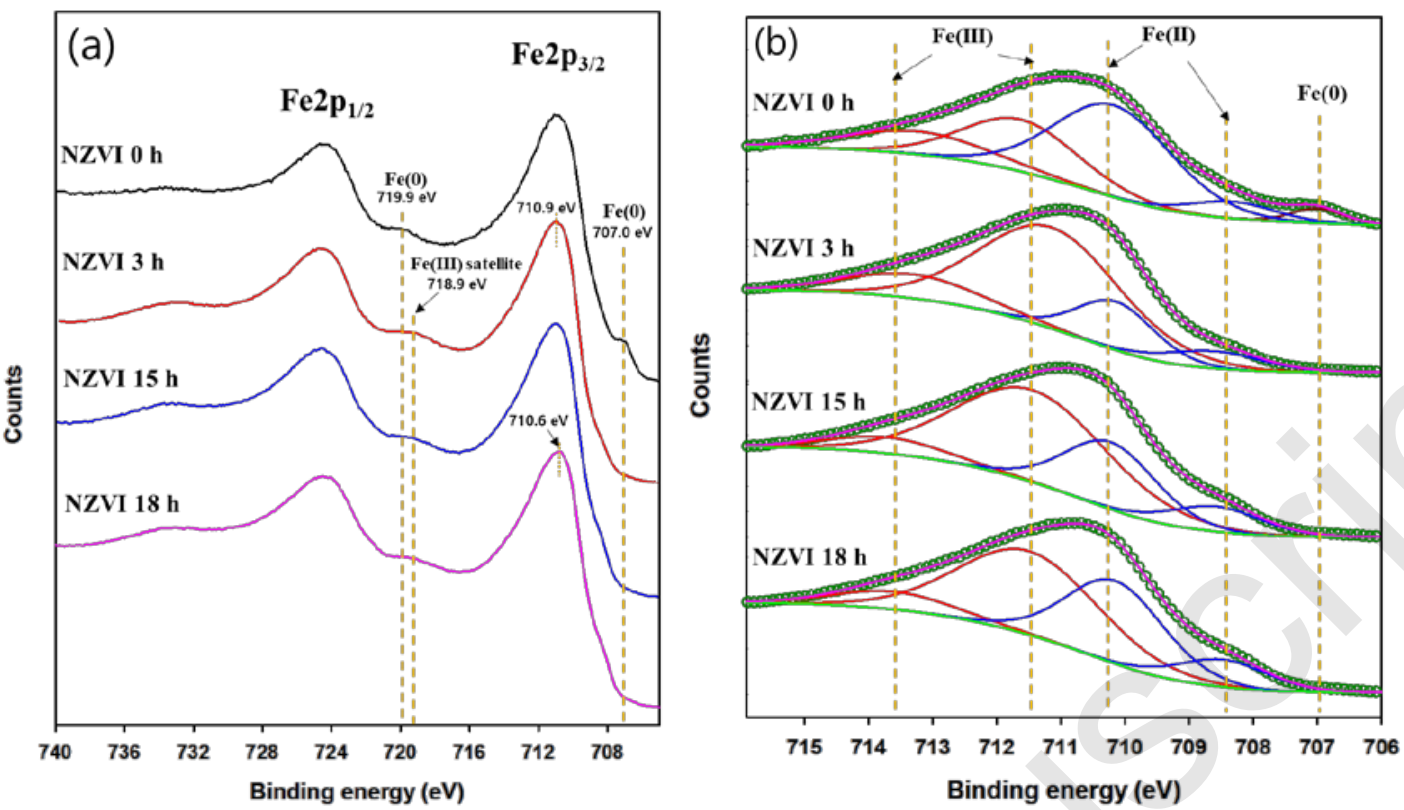

Figure 4. XPS spectra for (a) Fe2p of NZVI before and after reaction with $\mathrm{H}_{2} \mathrm{O}_{2}$ and (b) and the deconvolution results of $\mathrm{Fe} 2 \mathrm{p}_{3 / 2}(706-716 \mathrm{eV})$. Conditions: $\left[\mathrm{H}_{2} \mathrm{O}_{2}\right]=5 \mathrm{mM}$, $327 \quad[\mathrm{NZVI}]=0.2 \mathrm{~g} \cdot \mathrm{L}^{-1}$ 
340 (Figure 4(b)), underscoring the surface oxidation of NZVI by $\mathrm{H}_{2} \mathrm{O}_{2}$. However, the Fe(III)

341 satellite peak gradually decreased over reaction time (3 to $18 \mathrm{~h}$ ), whereas the peak of 342 Fe2p $3 / 2$ shifted to lower binding energy (710.9 $\rightarrow 710.6 \mathrm{eV})$ (Figure 4(a)). The 343 disappearance of Fe(III) satellite peak may result from mineral transformation of $\mathrm{Fe}^{\mathrm{III}}$ 344 oxides (e.g. maghemite) into magnetite as previously reported. ${ }^{48}$ Indeed, the proportion 345 of $\mathrm{Fe}(\mathrm{II})$ increased (34.7\% at $15 \mathrm{~h}$ to $43.3 \%$ at $18 \mathrm{~h})$, and Fe(III) decreased $(65.3 \%$ at $34615 \mathrm{~h}$ to $56.7 \%$ at $18 \mathrm{~h}$ ) with increasing reaction time (Figure $4 \mathrm{~b}$ ). Based on all experimental findings above, an oxidation pathway of NZVI by $\mathrm{H}_{2} \mathrm{O}_{2}$

348 can be proposed as two successive steps (Figure S5). In the early stage of NZVI 349 oxidation, highly oxidizing condition caused by the addition of a high dose of $\mathrm{H}_{2} \mathrm{O}_{2}$ can 350 form mixed valence oxides (i.e. magnetite), but also $\mathrm{Fe}^{\mathrm{III}}$-oxyhydoxides (lepidocrocite, 351 maghemite and hematite), resulting in change of NZVI suspension color from black to 352 yellowish (Figure 1). After the remained $\mathrm{H}_{2} \mathrm{O}_{2}$ was completely depleted over 15h of 353 reaction time, reducing conditions (ORP value reached the initial value of fresh NZVI 354 suspension) and then release of ferrous ions into solution concurrently take place 355 (Figure 1). Afterwards, the dissolved ferrous ions tend to re-sorb on the surface of $356 \mathrm{Fe}(\mathrm{III})$-oxyhydroxides at alkaline $\mathrm{pH}$ value, leading to their transformation into 357 magnetite as previously reported for lepidocrocite or hematite (Eqs. (5) and (6)). ${ }^{49,50}$ 
361 Color change from yellowish to black of suspension further suggested such 362 transformation into magnetite phase. Therefore, Fe(II)-release during the oxidation of 363 NZVI suspension and its re-adsorption to secondary minerals may influence the surface 364 reactivity of the resulting products.

365 Additional experiments of NA removal by fresh NZVI or oxidized products (Figure 366 S6) using Good's buffers showed that NA adsorption decreased with pH increasing. 367 However, the NA adsorption at pH 9 was much lower in buffered systems as compared 368 to the un-buffered NZVI suspension (Figure 1). This discrepancy is probably due to the 369 interactions of Good's buffers with the Fe oxide surfaces, which may cause the rapid $370 \mathrm{Fe}(0)$ corrosion and Fe(II) release. ${ }^{51}$ It was reported that such Fe(II) release may lead 371 to lepidocrocite formation through $\mathrm{Fe}(\mathrm{II})$-catalyzed transformation of poorly 372 crystallized Fe-oxides (e.g. ferrihydrite) and/or oxidation of Fe(II) at acidic-neutral $373 \mathrm{pH} .{ }^{51}$ Accordingly, lepidocrocite was identified here as the major phase in buffered 374 NZVI suspension at pH 5.6 and 7 (Figure S7). However, the oxidation products in 375 TRIZMA buffered system (pH 9) were mostly highly amorphous, which makes difficult 376 an accurate identification of secondary iron minerals (Figure S7). It is worth noting that 377 oxidation in TRIZMA buffered system led to dispersion of NZVI particles in suspension 378 and enhancement in zeta potential (Figure S8) compared to that without TRIZMA 379 (Figure S2), thus confirming interactions of TRIZMA molecules with Fe-oxides. 380 Therefore, interactions of organic buffer's molecules with mineral surfaces may affect 

and thus the surface bound Fe(II) can be preserved. This is consistent with previous

383 works which showed that organic buffers increased the Fe(II) apparent solubility in 384 goethite and magnetite suspensions even in the alkaline $\mathrm{pH}$ range. ${ }^{21-22}$ Collectively, 385 these results further suggest that the Fe(II) bound to secondary minerals (i.e. magnetite) 386 could control on the surface reactivity and then the binding capacity toward negatively 387 charged contaminants.

\subsection{NA adsorption mechanisms on secondary minerals}

To check the $\mathrm{pH}$ dependence of Fe(II) release and NA sorption onto the NZVI

391 oxidation products, residual concentrations of NA and dissolved Fe(II) in oxidized

392 NZVI suspension were monitored over a wide range of $\mathrm{pH}(6-11)$ (Figure 5). NA

393 adsorption was found the greatest between $\mathrm{pH} 6$ and 9, and the lowest between $\mathrm{pH} 10$

394 and 11. This $\mathrm{pH}$ adsorption edges differs from the previously reported data of NA 395 adsorption to Fe-oxyhydroxides ${ }^{20,26}$ or the NA adsorption data obtained here with three 396 synthetic Fe-oxyhydroxides (See Figure S9). Indeed, NA adsorption to non397 stoichiometric magnetite $\left(\mathrm{Fe}_{3} \mathrm{O}_{4}\right)^{26}$, goethite $(\alpha-\mathrm{FeOOH})^{20}$ or other ferric 398 oxyhydroxides (maghemite, hematite or lepidocrocite) decreased as increasing $\mathrm{pH}$ and 399 became negligible for $\mathrm{pH}$ higher than 9. Here, the $\mathrm{pH}$-adsorption curve of NA onto 400 NZVI oxidized products shifts to larger $\mathrm{pH}$ values, probably because of the presence of 401 dissolved Fe(II). The concentration of dissolved Fe(II) (no dissolved Fe(III) was found) 
402

decreased as $\mathrm{pH}$ increasing. Because of $\mathrm{H}^{+}$promoted dissolution of magnetite, $\mathrm{Fe}(\mathrm{II})$

dissolution takes place at low $\mathrm{pH}$, which can explain the high amount of dissolved Fe(II)

at that $\mathrm{pH}$ range. ${ }^{27}$ This observation falls in line with a previous investigation on the reactivity assessment of magnetite in presence of variable dissolved Fe(II) amounts ${ }^{26}$. Indeed, it was shown that Fe(II) recharge of magnetite enhanced its binding capacity towards organic and inorganic compounds, shifting the maximum sorption to alkaline $\mathrm{pH}$ values. ${ }^{26}$ Furthermore, Fe(II)-amendment of non-stoichiometric magnetite $(\mathrm{Fe}(\mathrm{II}) / \mathrm{Fe}(\mathrm{III})=0.40)$ led to similar sorption capacity as compared to the stoichiometric magnetite (i.e. $\mathrm{Fe}(\mathrm{II}) / \mathrm{Fe}(\mathrm{III})=0.50) .{ }^{26}$ In the present work, the $\mathrm{Fe}(\mathrm{II}) / \mathrm{Fe}(\mathrm{III})$ ratio of NZVI oxidized products determined by acid digestion was found very high (1.03) and much more than the expected ratio for a magnetite phase, probably because of the presence of residual traces of $\mathrm{Fe}^{0}$.
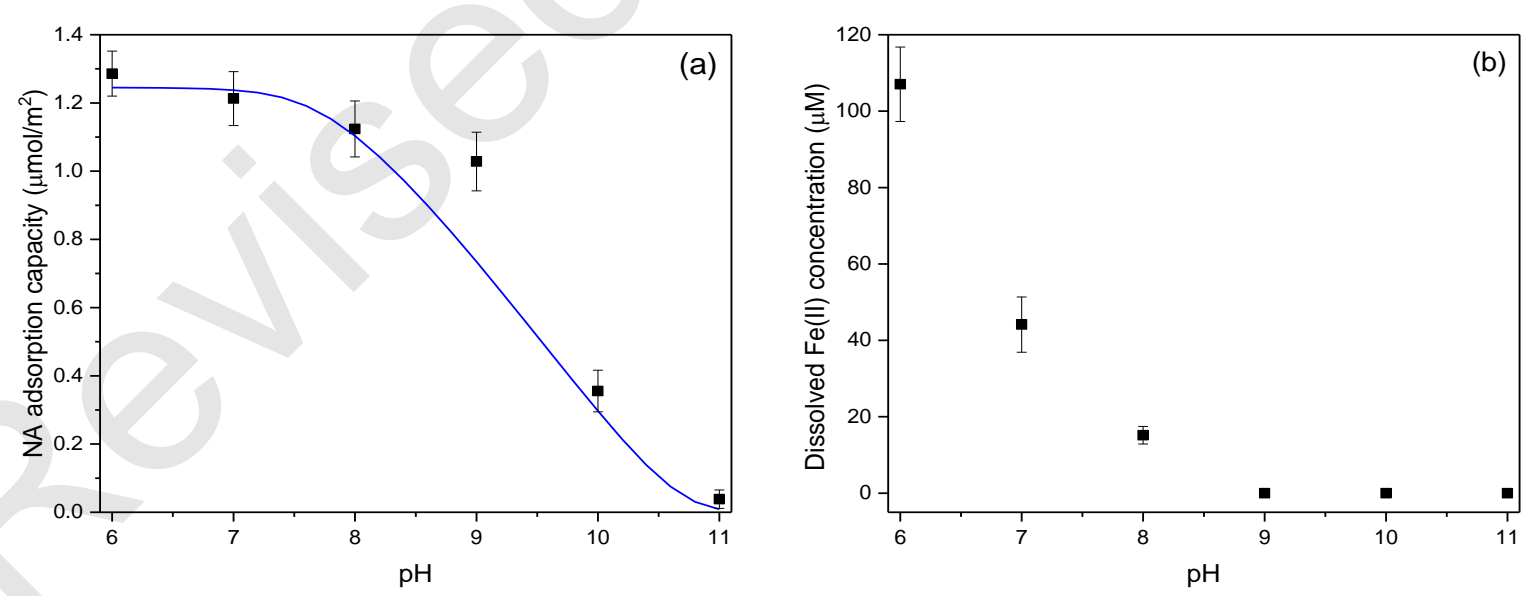

414 Figure 5. pH-dependency of (a) NA adsorption and (b) dissolved Fe(II) concentration 415 in NZVI suspension after oxidation $\left(5 \mathrm{mM} \mathrm{H}_{2} \mathrm{O}_{2}\right)$. Lines are modeling results. 416 Experimental conditions: [NZVI] $=0.2 \mathrm{~g} \cdot \mathrm{L}^{-1},[\mathrm{NA}]=10 \mu \mathrm{M}, 20 \pm 1^{\circ} \mathrm{C}$. The BET surface 417 area used here is that measured for the oxidized particles (using $5 \mathrm{mM}$ of $\mathrm{H}_{2} \mathrm{O}_{2}$ ) (28.2 $418 \pm 1.5 \mathrm{~m}^{2} / \mathrm{g}$ ). 

washing of NZVI products indicated strong loss of Fe(II) during the washing process. was observed after the washing process, confirming the crucial role of the surface bound $\mathrm{Fe}(\mathrm{II})$ in the enhanced NA adsorption.

As an attempt to explain the enhanced NA adsorption at high $\mathrm{pH}$ with respect to the presence of Fe(II), we used a surface complexation model, previously developed

428 for the stoichiometric magnetite. ${ }^{26}$ We assumed that NA binds to two surface hydroxo 429 groups $^{20,52}$ by involving its carboxylate and its keto-group as following:

$$
2 \equiv \mathrm{FeOH}+2 \mathrm{H}^{+}+\mathrm{NA}^{-} \rightleftharpoons(\equiv \mathrm{Fe})_{2} \mathrm{NA}^{+}+2 \mathrm{H}_{2} \mathrm{O} \quad{ }^{\mathrm{s}} \mathrm{K}
$$

434 adsorption by the oxidized NZVI particles was obtained at a wide $\mathrm{pH}$ range (6-11). We 435 used the measured dissolved Fe(II) concentration at the end of each adsorption 436 experiment as input parameters to account for NA-Fe(II) aqueous complex formation.

437 The good accuracy with the experimental data using the modeling parameters of the 438 stoichiometric magnetite (see Table S2) suggests that magnetite controls NA binding to 439 oxidized NZVI, and further confirms the key role of surface bound Fe(II). 
$441 \quad$ NZVI at alkaline $\mathrm{pH}$ values also concerns other antibiotics of contrasting structure and

442 properties. Indeed, great adsorption of TET (i.e. $70 \%$ removal of $10 \mu \mathrm{M}$ ) onto the 443 oxidized NZVI particles was observed at $\mathrm{pH} 9.0 \pm 0.2$ (Figure S11). Taken together, 444 these results highlight the key role of Fe(II) generated along the NZVI oxidation process 445 in promoting greater binding abilities of the secondary minerals.

NZVI oxidation or passivation in ambient environments can lead to either

449 formation of $\mathrm{Fe}^{\mathrm{II}}$-bearing phases on the NZVI surface or complete oxidation to ferric 450 (oxyhydr)oxides. Under the experimental conditions of this study, NZVI oxidation led 451 to formation of $\mathrm{Fe}^{\mathrm{II}}$-bearing secondary minerals, with magnetite as the major phase.

452 The latter exhibited higher adsorption ability for organic contaminants, in contrast to 453 the fresh NZVI. In addition, an unexpected great adsorption at alkaline $\mathrm{pH}$ values was 454 observed with the formed secondary Fe minerals. This behavior is due to the gradual 455 increase in $\mathrm{Fe}(\mathrm{II})$ content at the surface of magnetite phase over the reaction time. A 456 surface complexation model confirmed that NA adsorption onto the secondary 457 magnetite is due to the formation of surface bound $\mathrm{Fe}(\mathrm{II})$. If $\mathrm{Fe}(\mathrm{II})$ is released into 458 solution, the surface bound Fe(II) decreased together with the NA adsorbed amount at 459 alkaline $\mathrm{pH}$ values. As iron (oxyhydr)oxide-coated NZVI particles or Fe(II)-Fe(III) 
460 (oxyhydr)oxides may exhibit different adsorption affinities toward negatively charged 461 molecules (e.g. antibiotics) or positively charged compounds, more attention should be 462 paid to the reactivity assessment of passivated NZVI particles or corrosion products. 463 Therefore, the modeling of contaminant fate and transport should consider the impact 464 of these secondary Fe minerals on the mobility of emerging contaminants in soil and 465 groundwater.

466

467 Conflicts of interest

468 There are no conflicts to declare.

469

\section{Acknowledgements}

471 We acknowledge support from the National Research Foundation of Korea (project no.

472 NRF- NRF-2019R1C1C1003316). We gratefully acknowledge to Isabelle Soutrel 473 (LC/UV) and Vincent Dorcet (THEMIS platform) for the assistance.

474

475 Supplementary information: Additional information regarding oxidation and 476 adsorption kinetics, TEM images and XRD data, additional data on zeta potential and 477 average particle size measurements, and surface complexation model parameters. 


\section{References}

1. S. H. Joo, A. J. Feitz and T. D. Waite, Oxidative Degradation of the Carbothioate Herbicide, Molinate, Using Nanoscale Zero-Valent Iron. Environ. Sci. Technol., 2004, 38, 2242-2247.

2. J. Ma, D. He, R. N. Collins, C. He and T. D. Waite, The tortoise versus the hare Possible advantages of microparticulate zerovalent iron (mZVI) over nanoparticulate zerovalent iron (nZVI) in aerobic degradation of contaminants, Water Res., 2016, 105, 331-340.

3. S. Tsarev, R. N. Collins, E. S. Ilton, A. Fahy and T. D. Waite, The short-term reduction of uranium by nanoscale zero-valent iron (nZVI): role of oxide shell, reduction mechanism and the formation of $\mathrm{U}(\mathrm{V})$-carbonate phases, Environ. Sci. Nano, 2017, 4, 1304-1313.

4. D. He, J. Ma, R. N. Collins and T. D. Waite, Effect of Structural Transformation of Nanoparticulate Zero-Valent Iron on Generation of Reactive Oxygen Species, Environ. Sci. Technol., 2016, 50, 3820-3828.

5. T. Liu, X. Li and T. D. Waite, Depassivation of Aged Fe0 by Ferrous Ions: Implications to Contaminant Degradation, Environ. Sci. Technol., 2013, 47, 13712-13720.

6. T. Phenrat, T. Thongboot and G. V. Lowry, Electromagnetic Induction of Zerovalent Iron (ZVI) Powder and Nanoscale Zerovalent Iron (NZVI) Particles Enhances Dechlorination of Trichloroethylene in Contaminated Groundwater and Soil: Proof of Concept. Environ. Sci. Technol., 2016, 50, 872-880.

7. Y.-T. Wei, S.-C. Wu, C.-M. Chou, C.-H. Che, S.-M. Tsai and H.-L. Lien, Influence of nanoscale zero-valent iron on geochemical properties of groundwater and vinyl chloride degradation: A field case study, Water Res., 2010, 44, 131-140.

8. C. Su, R.W Pulsa, T. A. Krug, M. T. Watling, S. K. O'Hara, S. K; J. W. Quinnc and N. E. Ruiz, Travel distance and transformation of injected emulsified zerovalent iron nanoparticles in the subsurface during two and half years, Water Res., 47, 4095-4106.

9. W. X. Zhang, Nanoscale Iron Particles for Environmental Remediation: An Overview. J. Nanopart. Res. 2003, 5, 323-332.

10. B. C. Reinsch, B. Forsberg, R. L. Penn, C. S. Kim and G. V. Lowry, Chemical Transformations during Aging of Zerovalent Iron Nanoparticles in the Presence of Common Groundwater Dissolved Constituents, Environ. Sci. Technol., 2010, 44, 3455-3461.

11. J.-Y. Ahn, C. Kim, H.-S. Kim, K.-Y. Hwang and I. Hwang, Effects of oxidants on in situ treatment of a DNAPL source by nanoscale zero-valent iron: A field study, Water Res., 2016, 107, 57-65.

12. J. Chen, Z. Xiu, G. V. Lowry and P. J. J. Alvarez, Effect of natural organic matter on toxicity and reactivity of nano-scale zero-valent iron, Water Res., 2011, 45, 
1995-2001.

13. H. Pullin, R. A. Crane, D. J. Morgan and T. B. Scott, The effect of common groundwater anions on the aqueous corrosion of zero-valent iron nanoparticles and associated removal of aqueous copper and zinc, J. Environ. Chem. Eng, 2017, 5, 1166-1173.

14. A. Liu, J. Liu, J. Han and W.-x. Zhang, Evolution of nanoscale zero-valent iron (nZVI) in water: Microscopic and spectroscopic evidence on the formation of nano- and micro-structured iron oxides, J. Hazard. Mater., 2017, 322, 129-135.

15. C. Poppe, M. Ayroud, G. Ollis, M. Chirino-Trejo, N. Smart, S. Quessy and P. Michel, Trends in Antimicrobial Resistance of Salmonella Isolated from Animals, Foods of Animal Origin, and the Environment of Animal Production in Canada, 1994-1997, Microb. Drug Resist, 2001, 7, 197-212.

16. F. Campioni, R. A. Souza, V. V. Martins, E. G. Stehling, A. M. M. Bergamini and J. P. Falcão, Prevalence of gyrA Mutations in Nalidixic Acid-Resistant Strains of Salmonella Enteritidis Isolated from Humans, Food, Chickens, and the Farm Environment in Brazil, Microb. Drug Resist., 2016, 23, 421-428.

17. U. Schwertmann, R. M. Cornell, Iron Oxides in the Laboratory: Preparation and Characterization. Wiley- VCH: New York, 2000.

18. S. Bae, S. Gim, H. Kim and K. Hanna, Effect of $\mathrm{NaBH}_{4}$ on properties of nanoscale zero-valent iron and its catalytic activity for reduction of $\mathrm{p}$-nitrophenol, Appl. Catal., B, 2016, 182, 541-549

19. S. Bae and W. Lee, Influence of Riboflavin on Nanoscale Zero-Valent Iron Reactivity during the Degradation of Carbon Tetrachloride, Environ. Sci. Technol., 2014, 48, 2368-2376.

20. J. Xu, R. Marsac, C. Wei, F. Wu, J. F. Boily and K. Hanna, Cobinding of Pharmaceutical Compounds at Mineral Surfaces: Mechanistic Modeling of Binding and Cobinding of Nalidixic Acid and Niflumic Acid at Goethite Surfaces, Environ. Sci. Technol., 2017, 51, 11617-11624.

21. A. Buchholz, C. Laskov and S. B. Haderlein, Effects of Zwitterionic Buffers on Sorption of Ferrous Iron at Goethite and Its Oxidation by $\mathrm{CCl}_{4}$, Environ. Sci. Technol., 2011, 45, 3355-3360.

22. R. Marsac, M. Pasturel and K. Hann, Reduction Kinetics of Nitroaromatic Compounds by Titanium-Substituted Magnetite, J. Phys. Chem. C, 2017, 121, 11399-11406.

23. D. L. Parkhurst and C. A. J. Appelo, User's guide to PHREEQC (Version 2): A computer program for speciation, batch-reaction, one-dimensional transport, and inverse geochemical calculations, Water Resources Investigations Report, 1999, 99-4259,

24. W. R. Vincent, S. G. Schulman, J. M. Midgley, W. J. van Oort and R. H. A. Sorel, Prototropic and metal complexation equilibria of nalidixic acid in the physiological pH region, Int. J. Pharm., 1981, 9, 191-198. 
25. R. Jolsterå, L. Gunneriusson and A. Holmgren, Surface complexation modeling of $\mathrm{Fe}_{3} \mathrm{O}_{4}-\mathrm{H}^{+}$and $\mathrm{Mg}(\mathrm{II})$ sorption onto maghemite and magnetite, J. Colloid Interface Sci., 2012, 386, 260-267.

26. W. Cheng, R. Marsac and K. Hanna, Influence of Magnetite Stoichiometry on the Binding of Emerging Organic Contaminants, Environ. Sci. Technol., 2018, 52, 467-473.

27. S. Bae and K. Hanna, Reactivity of Nanoscale Zero-Valent Iron in Unbuffered Systems: Effect of pH and Fe(II) Dissolution, Environ. Sci. Technol., 2015, 49, 10536-10543.

28. Y.-H. Bai, Y. Du, J.-J. Xu and H.-Y. Chen, Choline biosensors based on a bielectrocatalytic property of $\mathrm{MnO}_{2}$ nanoparticles modified electrodes to $\mathrm{H}_{2} \mathrm{O}_{2}$, Electrochem. Commun., 2007, 9, 2611-2616.

29. T. A. Kurniawan and W.-h. Lo, Removal of refractory compounds from stabilized landfill leachate using an integrated $\mathrm{H}_{2} \mathrm{O}_{2}$ oxidation and granular activated carbon (GAC) adsorption treatment, Water Res., 2009, 43, 4079-4091.

30. N. V. Klassen, D. Marchington and H. C. E. McGowan, $\mathrm{H}_{2} \mathrm{O}_{2}$ Determination by the I3- Method and by $\mathrm{KMnO}_{4}$ Titration, Anal. Chem., 1994, 66, 2921-2925.

31. Y. Segura, F. Martínez, J. A. Melero and J. L. G. Fierro, Zero valent iron (ZVI) mediated Fenton degradation of industrial wastewater: Treatment performance and characterization of final composites, Chem. Eng. J., 2015, 269, 298-305.

32. W. Zhang, H. Gao, J. He, Y. Peng and X. Xu, Removal of norfloxacin using coupled synthesized nanoscale zero-valent iron (nZVI) with $\mathrm{H}_{2} \mathrm{O}_{2}$ system: Optimization of operating conditions and degradation pathway, Sep. Purif. Technol., 2016, 172, 158-167.

33. W. Cheng, E. L. Kalahroodi, R. Marsac and K. Hanna, Adsorption of Quinolone Antibiotics to Goethite under Seawater Conditions: Application of a Surface Complexation Model, Environ. Sci. Technol., 2019, 53, 1130-1138.

34. Q. Du, G. Li, S. Zhang, J. Song, Y. zhao and F. Yang, High-dispersion zero-valent iron particles stabilized by artificial humic acid for lead ion removal, J. Hazard. Mater., 2020, 383, 121170.

35. H. M. Ibrahim, M. Awad, A. S. Al-Farraj and A. M. Al-Turki, Stability and Dynamic Aggregation of Bare and Stabilized Zero-Valent Iron Nanoparticles under Variable Solution Chemistry, Nanomaterials, 2020, 10, 192.

36. H. Dong and I. M. C. Lo, Influence of humic acid on the colloidal stability of surface-modified nano zero-valent iron, Water Res., 2013, 47, 419-427.

37. E. S. Krystofiak, E. C. Mattson, P. M. Voyles, C. J. Hirschmugl, R. M. Albrecht, M. Gajdardziska-Josifovska and J. A. Oliver, Multiple Morphologies of GoldMagnetite Heterostructure Nanoparticles are Effectively Functionalized with Protein for Cell Targeting, Microsc. Microanal., 2013, 19, 821-834.

38. A. Liu, J. Liu, B. Pan and W.-x. Zhang, Formation of lepidocrocite ( $\gamma$-FeOOH) from oxidation of nanoscale zero-valent iron (nZVI) in oxygenated water, RSC 

Adv., 2014, 4, 57377-57382.

39. R. P. Araújo-Neto, E. L. Silva-Freitas, J. F. Carvalho, T. R. F. Pontes, K. L. Silva, I. H. M. Damasceno, E. S. T. Egito, A. L. Dantas, M. A. Morales and A. S. Carriço, Monodisperse sodium oleate coated magnetite high susceptibility nanoparticles for hyperthermia applications, J. Magn. Magn. Mater., 2014, 364, 72-79.

40. Y. Lalatonne, J. Richardi and M. P. Pileni, Van der Waals versus dipolar forces controlling mesoscopic organizations of magnetic nanocrystals, Nat. Mater., 2004, 3, 121-125.

41. M. I. Dar and S. A. Shivashankar, Single crystalline magnetite, maghemite, and hematite nanoparticles with rich coercivity, RSC Adv., 2013, 4, 4105-4113.

42. S. Bae, R. N. Collins, T. D. Waite and K. Hanna, Advances in Surface Passivation of Nanoscale Zerovalent Iron: A Critical Review, Environ. Sci. Technol., 2018, 52, 12010-12025.

43. Y. Liu and G. V. Lowry, Effect of particle age ( $\mathrm{Fe}^{0}$ content) and solution $\mathrm{pH}$ on NZVI reactivity: H2 evolution and TCE dechlorination, Environ. Sci. Technol., 2006, 40, 6085-6090.

44. M. A. Kumar, S. Bae, S. Han, Y. Chang and W. Lee, Reductive dechlorination of trichloroethylene by polyvinylpyrrolidone stabilized nanoscale zerovalent iron particles with Ni, J. Hazard. Mater., 2017, 340, 399-406.

45. S. Luo, T. Lu, L. Peng, J. Shao, Q. Zeng and J.-D. Gu, Synthesis of nanoscale zero-valent iron immobilized in alginate microcapsules for removal of $\mathrm{Pb}$ (II) from aqueous solution, J. Mater. Chem. A, 2014, 2, 15463-15472.

46. T. Yamashita and P. Hayes, Analysis of XPS spectra of $\mathrm{Fe}^{2+}$ and $\mathrm{Fe}^{3+}$ ions in oxide materials, Appl. Surf. Sci., 2008, 254, 2441-2449.

47. T. Radu, C. Iacovita, D. Benea and R. Turcu, X-Ray Photoelectron Spectroscopic Characterization of Iron Oxide Nanoparticles, A Appl. Surf. Sci., 2017, 405, 337343.

48. F. Kraushofer, Z. Jakub, M. Bichler, J. Hulva, P. Drmota, M. Weinold, M. Schmid, M. Setvin, U. Diebold, P. Blaha and G. S. Parkinson, Atomic-Scale Structure of the Hematite $\alpha$-Fe2O3(1102) "R-Cut” Surface, J. Phys. Chem. C, 2018, 122, 16571669.

49. M. Usman, M. Abdelmoula, K. Hanna, B. Grégoire, P. Faure and C. Ruby, Fe ${ }^{\mathrm{II}}$ induced mineralogical transformations of ferric oxyhydroxides into magnetite of variable stoichiometry and morphology, J. Solid State Chem., 2012, 194, 328-335.

50. J. P. Jolivet and E. Tronc, Interfacial electron transfer in colloidal spinel iron oxide. Conversion of $\mathrm{Fe}_{3} \mathrm{O}_{4}-\gamma \mathrm{Fe}_{2} \mathrm{O}_{3}$ in aqueous medium, J. Colloid Interface Sci., 1988, 125, 688-701.

51. C. He, D. He, R. N. Collins, S. Garg, Y. Mu and T. D. Waite, Effects of Good's Buffers and $\mathrm{pH}$ on the Structural Transformation of Zero Valent Iron and the Oxidative Degradation of Contaminants, Environ. Sci. Technol., 2018, 52, 13931403. 
641

642

643

644
52. R. Marsac, S. Martin, J.-F. Boily and K. Hanna, Oxolinic Acid Binding at Goethite and Akaganéite Surfaces: Experimental Study and Modeling, Environ. Sci. Technol., 2016, 50, 660-668. 